\title{
A REVIEW ON THE PERFORMANCE AND COMFORT OF STAB PROTECTION ARMOR
}

\author{
Dereje Berihun Sitotaw ${ }^{1}$, Dustin Ahrendt ${ }^{2}$, Yordan Kyosev², ${ }^{2,}$ Abera Kechi Kabish ${ }^{1}$ \\ 1 Ethiopian Institute of Textile and Fashion Technology, Bahir Dar University, Bahir Dar, Ethiopia \\ 2 Institute of Textile Machinery and High Performance Material Technology, Chair of Ready-Made Technology, Technische Universität Dresden, \\ 01062 Dresden, Germany \\ *Corresponding author. E-mail: dereje.berihun@bdu.edu.et
}

\begin{abstract}
:
Stab-protective clothing is the most important component of safety equipment and it helps to save the lives of its wearers; therefore, it is designed to resist knife, nail, or needle attacks, especially to the upper body. In this paper, the essential requirements for stab-resistant armor are investigated based on an in-depth review of previous research and prototype test results. The combination of protection and comfort in armor vests is a particularly challenging task. Review of the state of the art technology responsible for the manufacture of stab-resistant clothes has revealed that their design and development should encompass the elements of comfort, freedom of movement, permeability, absorption, evaporation, and weight reductions to ensure excellent ergonomics and high wear comfort. The design as well as the production, weight, thickness, material types and properties, and the arrangement of scales determine the level of protection and comfort offered by stab-resistant vests. Currently, the production of stab-proof gear-based 3D printing technology is evaluated, using lightweight materials (aramid) in the form of segmented scales inspired by nature. As the protection performance and wear comfort of stab-proof gear is enhanced, the willingness of security, control, transport, custom, and correction officers to wear them can be significantly increased in an endeavor to ensure that fatal injuries will decrease significantly.
\end{abstract}

\section{Keywords:}

Stab-protection and comfort, bio-inspired, lightweight, concealment, weapons

\section{Introduction}

Stab-protective clothing is a vital component of safety equipment that helps to save the lives of its wearers. A stab vest is a reinforced piece of body armor designed to resist attacks to the upper parts of the body (chest, back, and sides). It can be worn underneath or over clothing and offers protection against stabbing with sharp-tipped knives, needles, nails, and other sharp objects.

Early humans used comparatively primitive armors, which were manufactured out of metal, horn, wood, or leather lamellae [1, 2], but as civilizations developed and techniques advanced, body armor evolved. Then, in the last century, with its two world wars, various attempts were made to advance the technology of body armor [1]. It was reported that the first soft body armor was developed by the Japanese and, in that instance, was made of silk and was most effective against lowvelocity bullets [3]. The first so-called bullet-proof vests were designed in America in the two decades following World War I $[4,5]$. Modern police body armor was introduced into practice in the 1970s as a result of the US National Institute of Justice (NIJ)-funded research [6].

Research indicates that an officer who is not wearing body armor is 3 to 4 times more likely to suffer a fatal injury if stabbed in the torso than an officer who is wearing body armor. Thus, police officers, military, transport, and correction administrators should encourage their staff to wear stab vests during the whole duty shift [7].

The level of protection required in soft and sensitive body regions is determined by the type of attacks that are likely to be encountered [8]. Though corresponding guidelines exist, the design of appropriate stab vests with the desired level of protection can be challenging for a wide range of weapons that are used for puncture, and the stabbing techniques are different depending on assailants [9].

In addition to stab protection, body armors should be selected for comfort, flexibility, and other ergonomic issues for acceptance in accompaniment with coverage and service life [10-12]. The stab-protective vest should maintain body temperature through the thermal balance of heat generated by the body and transferring it to the environment $[13,14]$. Thermal resistance, water-vapor resistance, moisture transfer, air permeability, surface friction, size, fit, locomotion, and flexibility are the most important comfort-determining factors $[15,16]$ to enhance the function of vests, when these factors are considered during designing.

Protection and comfort are always conflicting. It is a well-known fact that a high level of protection from attacks is typically 
achieved at the expense of physiological comfort [17], which reduces the working period and efficiency of the wearer [12].

The selection of advanced materials (both for performance and for comfort) and appropriate armor design should ideally allow the flow of excessive metabolic heat away from the body (thermo-physiological property), which can be reflected by a combination of air permeability, thermal resistance, and moisture evaporation [18-20]. The increase in the stab resistance was attributed to the coating that bound the reduced micro-porous nature of the cloth and its raw material, increased thickness, and bending resistance that resulted in reduced comfort properties [20].

To be thermally comfortable when the body is heating up and sweating, the stab-protective vest should be able to eliminate the excess heat generated within the body to the atmosphere $[13,15,20,21]$. Tactile comfort, i.e., the feel or sensation on the skin when worn, is affected by the type of fiber and should be considered [22], as well as the chemical finish [23], type of fabric, and fabric structure [22].

The use of body armor has always been an issue in terms of ease of body movement and cognitive functions [24, 25], which should not be drastically compromised by the design of the protective armor [12].

\section{Determinants of protection and comfort of armors}

\subsection{Concealment for protection and comfort}

The compatibility of protective armors and other equipment should be evaluated in addition to freedom of movement and appropriateness of the design (overlap between jacket and trousers, arm length). Manufacturers should produce customized vests for wearers with different body types, to ensure that maximum benefit is achieved [26].

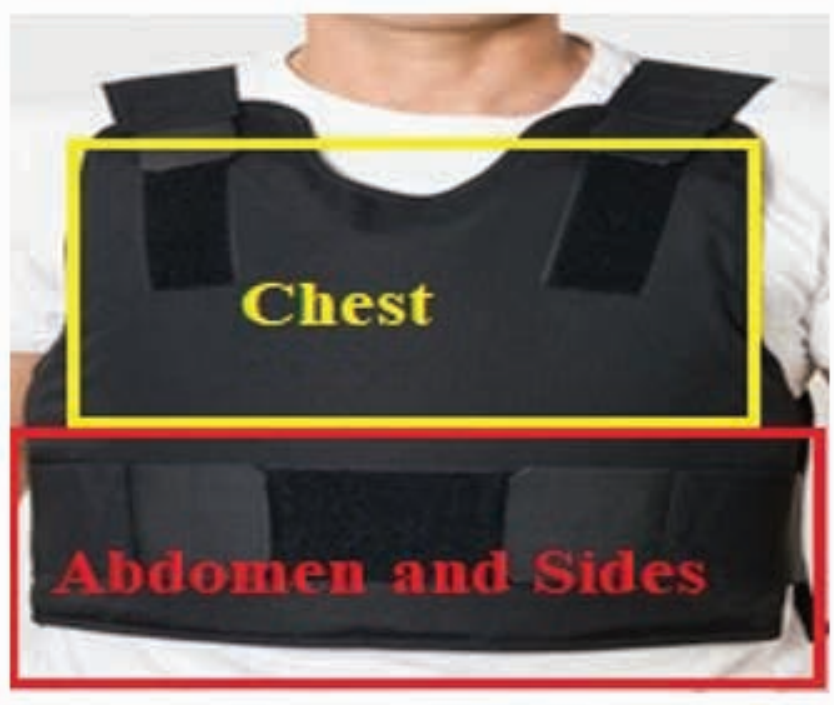

Figure 1. Concealable body armor: stab-proof vest [27].
The majority of stab attacks are directed at the chest and abdomen area, which can cause serious injuries, often leading to death [28-33], for which reason body armors are designed to protect these areas in particular, as shown in Figure 1 [34]. Besides the torso, head (including face), and arms are most likely to be attacked, followed by neck, shoulder, and legs that are also very vulnerable to stab attacks [35]. As shown in Figure 2 , the neck and shoulder areas are not covered by armor vest because the currently available stab-resistant materials would lead to physiological and operational constraints [36, 37]. Therefore, advancements in materials and design are required, for example, based on 3D body scanning and $3 \mathrm{D}$ printing technologies.

\subsection{Characteristics of weapons for stabbing}

The majority of stabbing incidents are performed using domestic knives, such as kitchen knives, lock knives, sheath knives, pen knives, and other variations [19, 38]. Different types of stabbing and spiking domestic knives are presented in Figure 3.

Generally, each stabbing weapon has a blade and a handle designed to suit its intended purpose for medical procedures, domestic use, manufacturing, training, and attacking, whereby the overall performance essentially depends on the blade [39]. The physical condition and skill of the attacker in addition to the characteristic features of a blade, such as the material it is made of, thickness, profile of the tip (i.e., angle of the point), attacking angle, and sharpness of the edge, affect the severity of any attack and determine the type of armor to be designed [39-42]. Body armors that pass standard testing may still fail in case of a real attack due to changing parameters, for example, if knives are thrown manually or propelled mechanically at the target from different distances [43]. Moreover, the point and edge of a knife play significant roles during the basic mechanism of cutting (compressive pressure) [38, 44, 45]. Advanced stab-resistant armors protect their wearers against different types of knives.

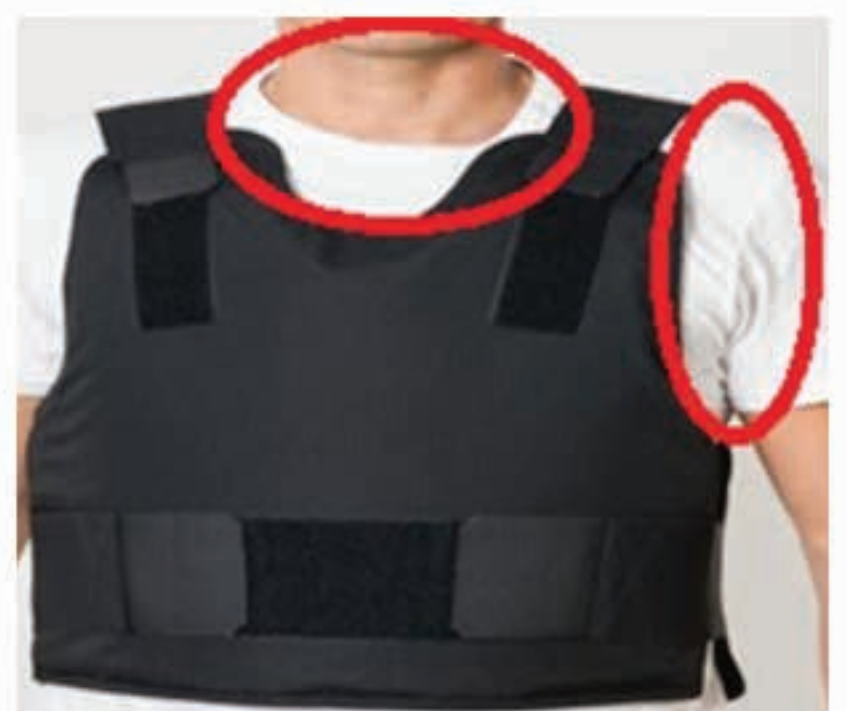

Figure 2. Shoulder and neck are not covered by standard stab vests [27]. 


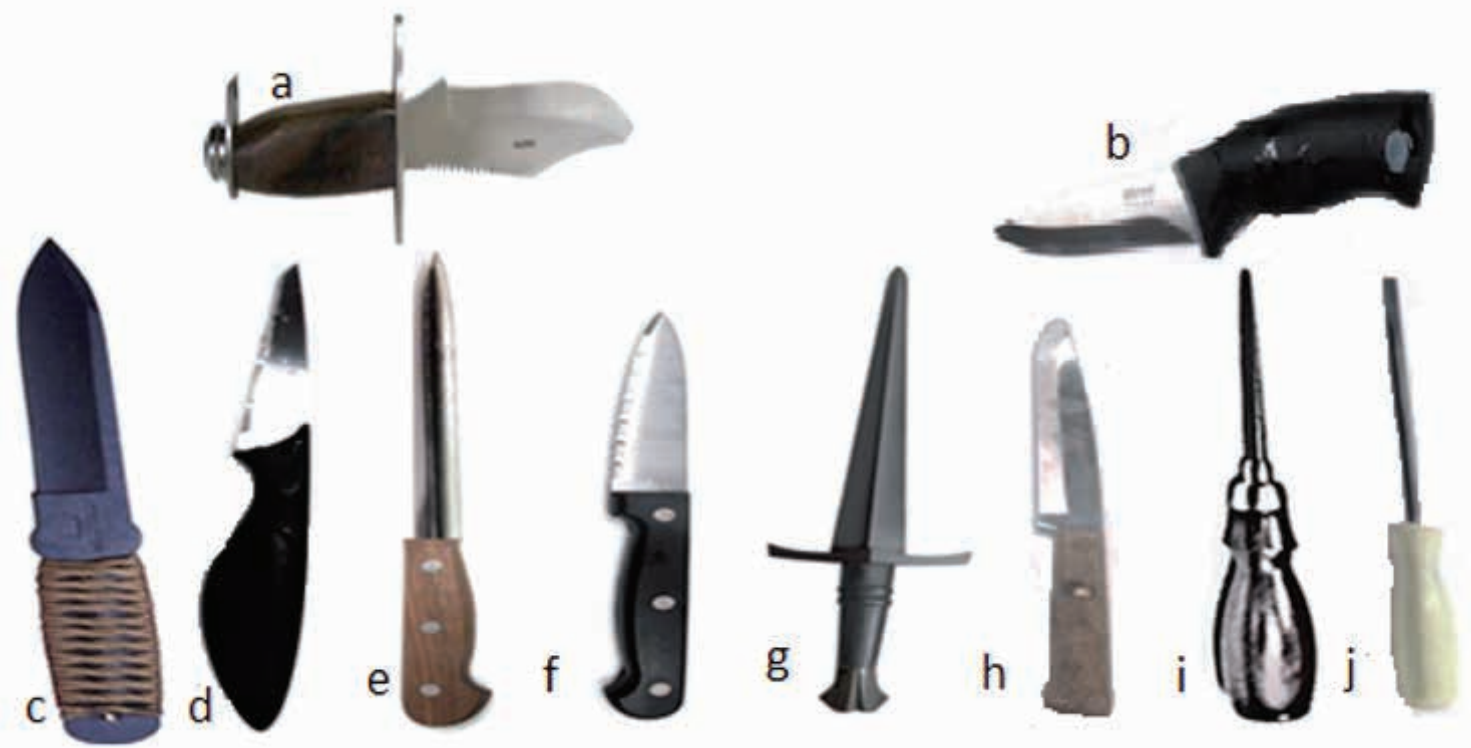

Figure 3. Various stabbing weapons: (a) lock knife (b) sheath knife (c) combat blade (d, f, h) kitchen knives, (e) pointed weapon, (g) dagger, (i) awl, and (j) screw driver.

\subsection{Design of stab-resistant armor types}

Many biological systems possess hierarchical and fractal-like interfaces and joint structures that bear and transmit loads, absorb energy, and accommodate growth, respiration, and/or locomotion [46].

A diversity of geometrically structured interfaces and joints is found in biology, for example, in the form of bone and armored exoskeletons [47, 48], the cranium [49, 50], the turtle carapace [51] and algae [52]. Mechanical and biological activities such as growth, motion, protection, load transmission, and energy absorption are determined by their geometry $[49,50,53]$.
Learning by imitation and further by linking of data has probably been one of the most productive ways of development to be deployed. In the case of bio-inspired flexible protection, segmented armors from fish (Figures $4 \mathrm{a}$ and $4 \mathrm{~b}$ ), alligators (Figures $4 \mathrm{c}$ and $4 \mathrm{~d}$ ), snakes, Tonicella marmorea (Figures 8 and 9), pangolin, scaly-foot gastropods (Figure 5), species of Arapaima (Figure 6), and armadillos (Figures $4 \mathrm{e}$ and 4f) are attracting an increasing amount of attention owing to their unique and highly efficient protective systems that resist mechanical threats from predation, while combining hardness, flexibility, breathability, thinness, puncture-resistance, and lightweight [53-58]. The extreme contrast between extremely stiff, hard scales and surrounding soft tissues gives rise to unusual and attractive mechanisms, which now serve as models for the design of bio-inspired armors. Despite this growing (a)

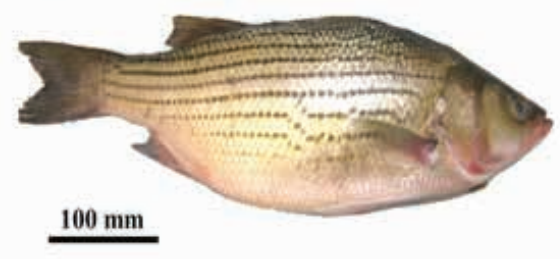

(b)

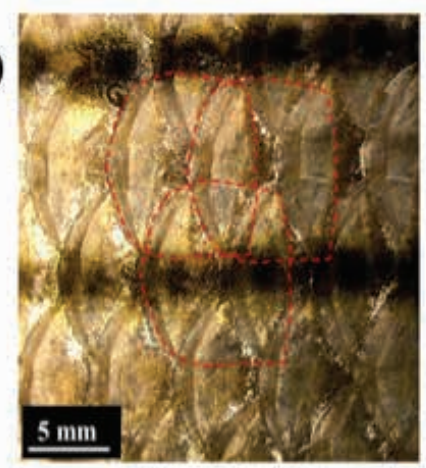

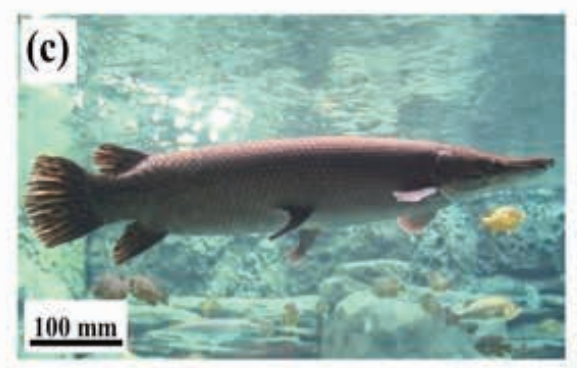

(d)

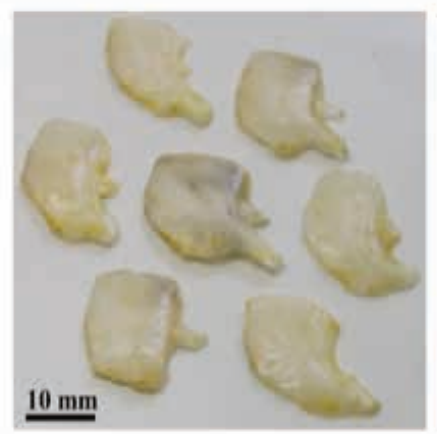

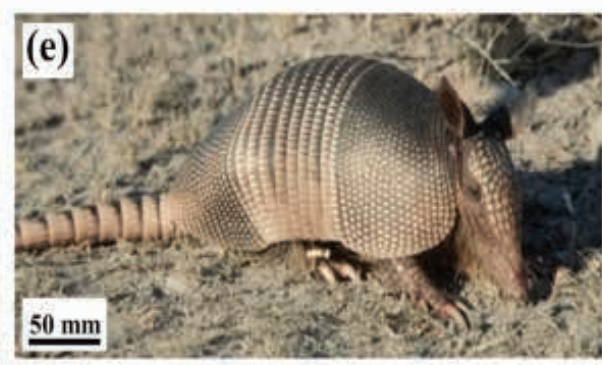

(f)

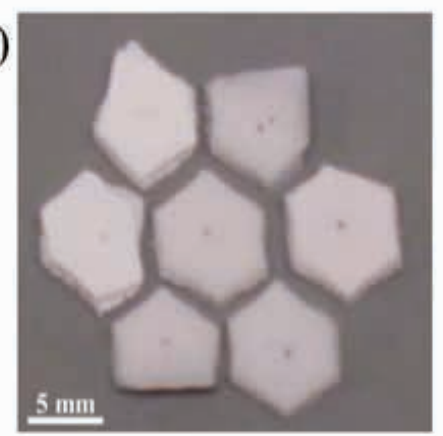

Figure 4. Examples of segmented armors found in nature: (a), (b) Striped bass with detailed arrangement of scales and geometry (c), (d) Alligator gar with details of scales; (e), (f) Armadillo with details of bony plates [59]. 

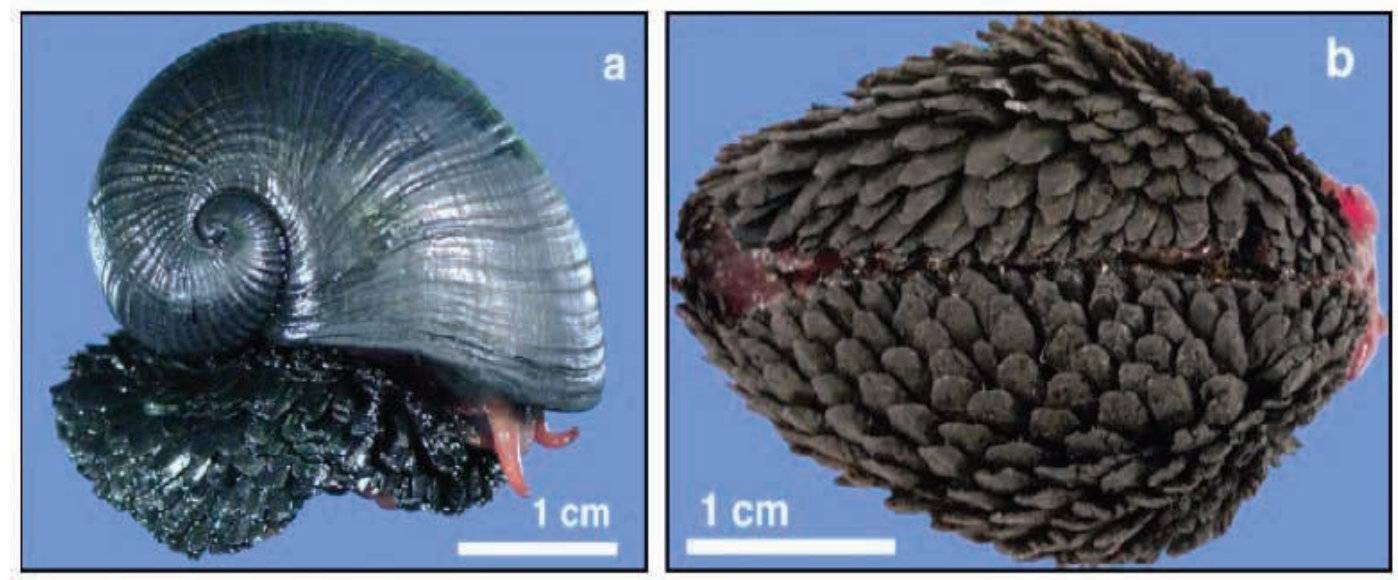

Figure 5. "Scaly-foot" gastropods top (a), and underside (b) [60].

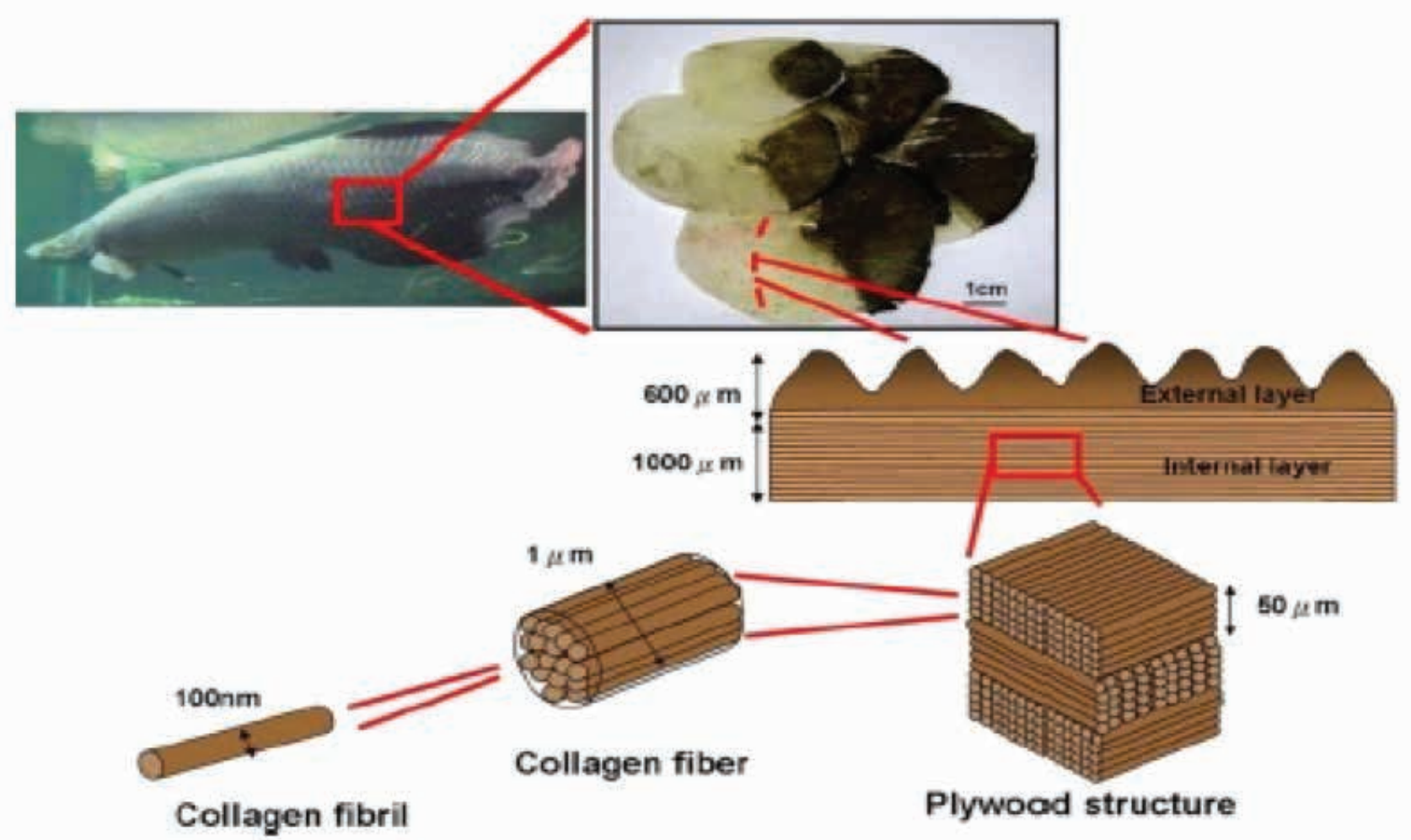

Figure 6. Hierarchical structure of Arapaima scales [57].

interest, currently limited guidelines are available for the choice

of materials, thickness, size, shape, and arrangement for

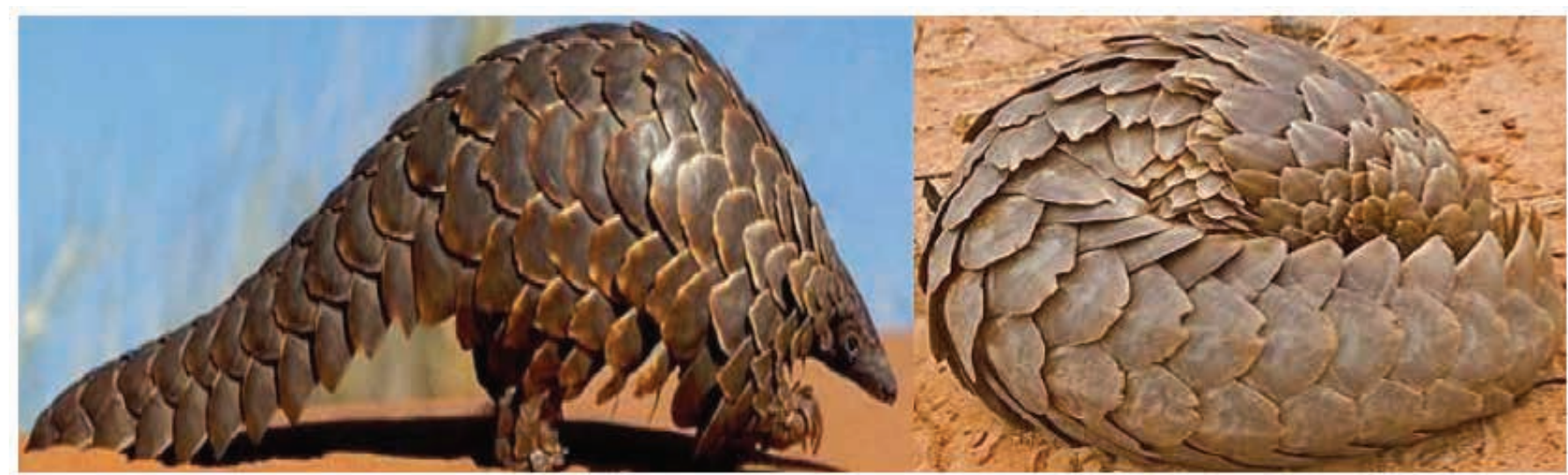

Figure 7. Demonstrating the flexibility of pangolin armor [61]. 

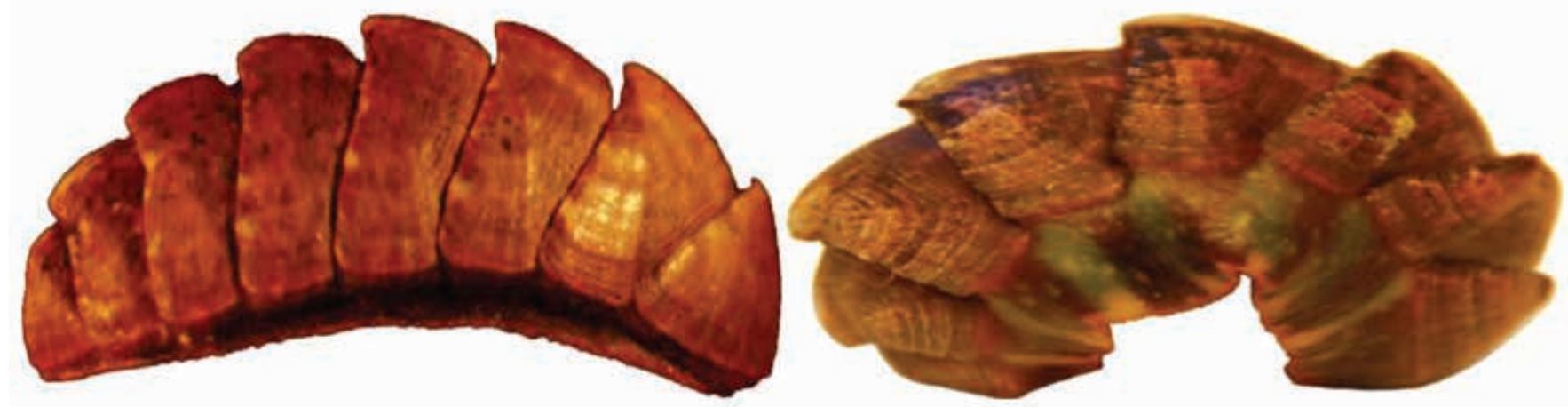

Figure 8. Images of Chiton Tonicella marmorea: (a) side view optical microscopy image of a dried shell; (b) side view photograph of a recently thawed chiton in a defensive, curved posture [58].
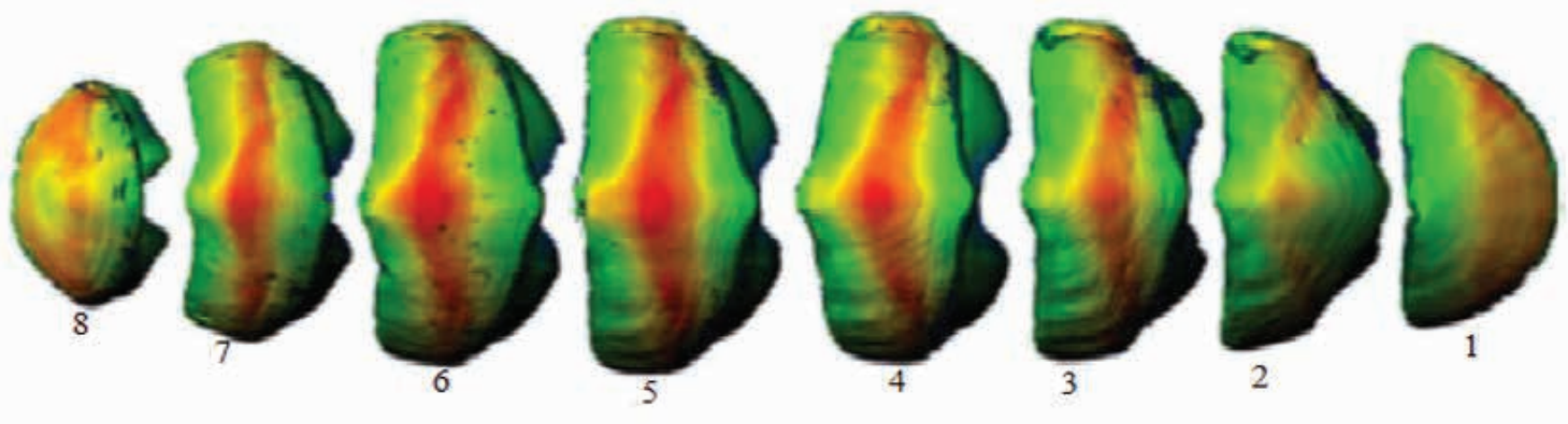

Figure 9. Thickness distribution of the armor plate assembly of Tonicella marmorea presented in dorsal view of the spatial distribution of thickness for each plate (1-8) [58].

protective scales [59].

Researchers studied the structure of individual scales and their arrangement (scalation pattern), using the example of a striped bass (Mimetes Saxatilis), a common teleost fish originating from the Northern Atlantic Ocean, which provides basic knowledge for future biomimetic "artificial scales" such that the resistance to puncture of individual scales is equally as important as their overlap and arrangement in providing efficient protection [56]. Similarly, protective gear for the human torso should be designed for ultimate protection, while providing the required flexibility, locomotion, and permeability to air and moisture.

\subsection{Interactions between scales and segmentation}

Segmented armors allow for much greater flexibility of movement, and they are therefore found in animal species with relatively fast locomotion; however, such armors still provide high surface hardness to prevent the teeth of potential predators from penetrating the soft underlying tissues and vital organs [59,62], in which individual segments display highly efficient structures and mechanisms. Shape optimization may be coupled with material choice, size and thickness of the scales, and attachments of the scales to design, thus producing high-performance bio-inspired flexible armors [59].

The scale-scale interactions can significantly increase the resistance to puncture due to the improved stability, and these interactions can be maximized by tuning the geometry and arrangement of the scales [63]. Interestingly, the designs that offer the best combinations of puncture resistance and flexural compliance are similar to the geometry and arrangement of natural teleost and ganoid scales (see Figure 10), which suggests that natural evolution has shaped these systems to maximize flexible protection $[64,65]$.

Structured interfaces are prevalent throughout nature and give rise to many remarkable mechanical properties in a number of biological materials [46, 53, 63, 66-68]. The materials, shape, size, and arrangement of the scales also influence the flexural response of the whole scales of skin, in which the scales surrounding the puncture redistribute the puncture force over large surfaces and volumes in the soft tissue [54, 66, 69]. This mechanism of scale interaction and force dispersal prevents unstable localized deformation of the skin and damage to underlying tissues [56, 70]. Due to additive manufacturing technologies that enable printing on individually assembled soft base materials, the geometric design of interlocking structures combined with material elongation allows for overlapping effects [37].

Therefore, protective gear involving segmented scales (see Figure 11) will provide better protection and comfort to a human torso than a vest made of a single piece of stab-resistant material, e.g., ceramics, polycarbonate sheet, or other metals. However, the performance of segmented scales for stab protection depends on the thickness of scales and the type of materials used for $3 D$ printing. A research study presented the 


\section{Ganoid Scales}

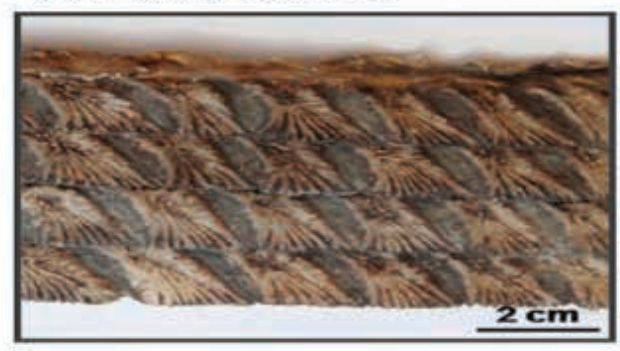

\section{Elasmoid Scales}
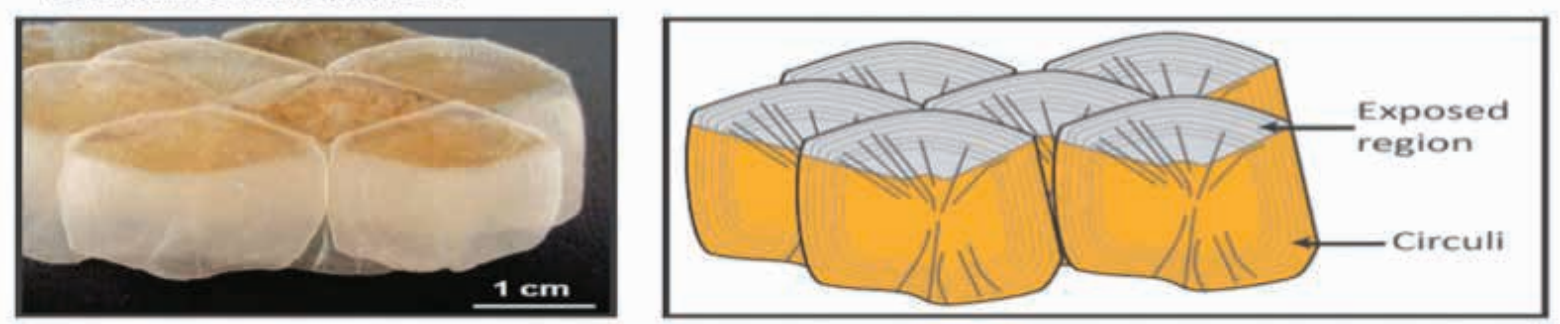

Figure 10. Examples of ganoid and elasmoid scales [65].

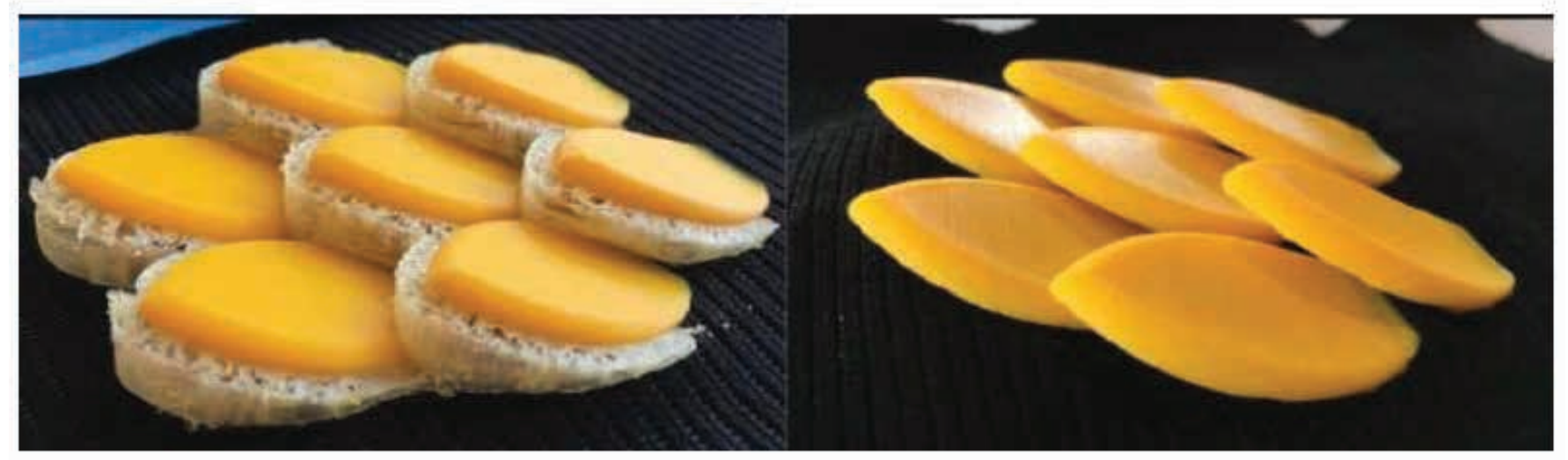

Figure 11. Scale-like elements with water-soluble support (left) and overlapping effects (right) [37].

scales of 3D printed from aramid fiber with different thicknesses, and the result revealed that a scale with $2 \mathrm{~mm}$ thickness failed to resist the stabbing blade, whereas the scales with $4 \mathrm{~mm}$ and $6 \mathrm{~mm}$ thickness resist the puncture of a knife at impact energy of 25 joules [37]. Segmented scales increase thermal comfort by allowing the transport of moisture away from the body [14, 71]. The human body requires elimination of excess heat from the body through the dry heat losses and perspiration from the body to the environment, which depend on the air gap between the skin and garment layers. These air gaps should be determined during designing and attachment of segmented scales to improve the comfort of body armors [14, 21, 72, 73].

\subsection{Materials for the production of stab-protection armor}

Stab- and puncture-resistant soft body armor commonly employs multiple layers of densely woven fabrics or closely spaced laminated layers to dissipate the energy of an impact [74]. A stab-resistant body armor panel should afford protection against injury from penetration, while ensuring that the movement of the wearer is not excessively restricted. The impact force should be effectively spread from the point of impact over a greater area of the armor [75-77]. Materials designed for stab protection should absorb all the stab energy prior to penetration $[69,76,77]$. A typical stab-resistant system used for industrial protection is several millimeters thick and composed of knitted aramid fabric impregnated with thermoplastic polymers [78].

Some research studies encourage the use of much harder materials, such as high-density ceramics, to prevent bodily injury arising from impacts caused by sharp objects made of steel or other hard materials penetrating the protective armor [59]. Modern soft body armor consists of multiple layers of fabrics made from expensive high-performance fibers, for example, aramid, glass, polybenzoxazole, light para-aramid, and high-performance polyethylene, as an outer cover, while cotton, polyester, or wool are used to ensure good breathability and durability [78-81]. Most of the flexible protective systems used today are based on advanced textiles involving aramid and polyethylene fibers [82].

Shape optimization may be coupled with material choice, thus producing high-performance bio-inspired flexible armors [59]. Suitable yarns and fibers for making body armor fabric for multithreat vests are available [4, 83-87]. Moreover, natural fibers such as wool and cotton are combined with aramid material for enhanced wear comfort in terms of thermal conductivity, 


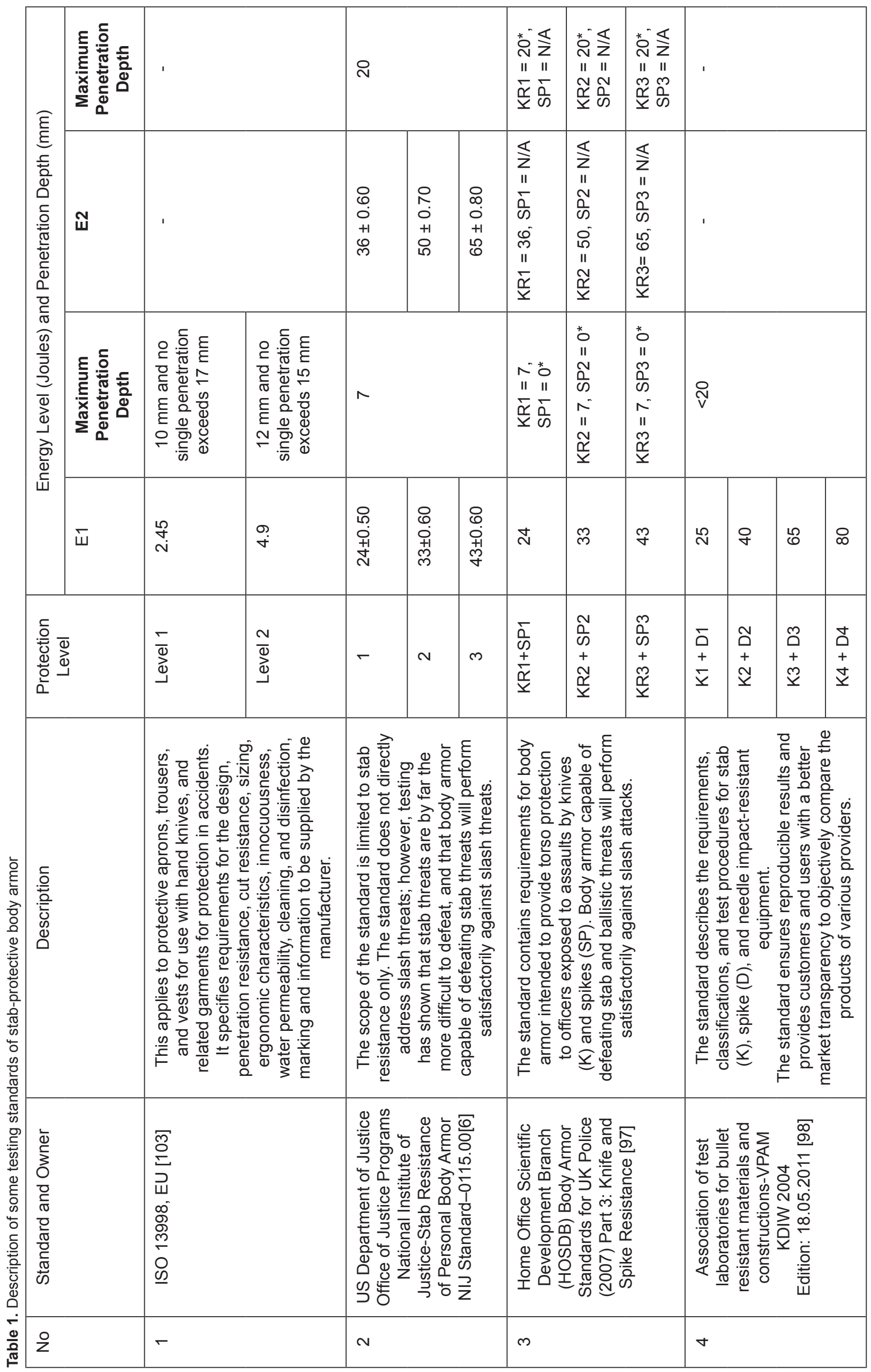


vapor transportation, air permeability, high moisture content, and insulation [88, 89]. Another research study concluded that inserting wool into a twill woven protection panel can lead to achieving acceptable stab depth values with fewer layers because wool is prevents yarn from sliding on the aramid layer below. This leads to weight reduction and improved wear comfort of the soft panels [90]. A suitable material selection is essential to design and develop armors with high protection performance for a specific energy level and wear comfort.

\subsection{Weight of stab-resistant armor}

Various factors affect the freedom of movement of individual body parts, including the number of layers, thickness of each fabric layer, clothing system design, and the relative ease of fitting between body dimensions and clothing [42, 91]. As the number of layers, physical bulk, and overall weight of the clothing system tend to increase, mobility is reduced, which can cause pain in several body parts, e.g., neck, back, and shoulder. The design might include front pockets for extra equipment, an adjustable abdominal belt, zippers, or adjustable straps for convenient wearability, which additionally increase weight. A stab-proof body armor panel that is made of a multilayered fabric assembly might exceed 40 layers and have a total weight varying from $1 \mathrm{~kg}$ to $10 \mathrm{~kg}$ depending on the armor type and protection level required [35, 92]. For low-energy threats, the number of layers can be reduced, which makes it easier to assemble a complete multilayer garment.

It was reported that users were reluctant to wear an uncomfortable protective vest [93]. Therefore, the interaction between the protective vest and the body is an important factor that needs to be considered when designing body armor. Advanced body armor technologies aim to reduce body armor vest weight to enhance the wearer's comfort level [73, 75, 94]. Evaporation of sweat over a large percentage of the body area could be improved by reduced weight and thickness of body armor vest [95].

The addition of advanced materials to the material mix improved stab resistance due to the improved mechanical properties of the end product and a high aspect ratio. For example, a stab-proof material made of laser-sintered polyamide/carbon fiber with a plate thickness of $6.5 \mathrm{~mm}$ and a pyramid angle of $30^{\circ}$ appeared to be the optimum composition for the desired application. Its area density was $6.58 \mathrm{~kg} / \mathrm{m}^{2}$, leading to a $43 \%$ weight reduction compared to conventional stab-resistant body armor [96]. Lightweight, free motion, flexibility, improved breathability as well as a high protection performance of armor materials can be achieved in future research projects.

\section{Evaluation of stab-resistant armors}

The performance of stab-protective armors is assessed for its protection and comfort using testing standards. This helps to determine the protection level of armors for a specified impact energy applied by attackers. The widely used test standards are US Department of Justice, NIJ-Stab Resistance of Personal Body Armor NIJ Standard-0115.00 [6], Home Office Scientific
Development Branch (HOSDB) Body Armor Standards for UK Police (2007) Part 3: Knife and Spike Resistance [97], and Association of Test Laboratories for Bullet Resistant Materials and Constructions-VPAM KDIW 2004 [98]. These standards present the scope and evaluation procedures of the protection level, striking energy (see Table 1), number and size of specimens, backing material, maximum allowable penetration depth of knife through each specimen, and test conditions.

The main comfort parameters of body armor such as air permeability, thermal transmission, water resistance, and flexibility of armor are evaluated according to ASTM-D737:2004 [99], ASTM-D5470:2017 [100], ISO-811:2018(en) [101], and ASTM-D1388:2018 [102], respectively.

\section{Conclusion}

Stab-resistant body armors are crucially important for saving the lives of police officers, correction officers, transport officers, and customs officials. Although the vast majority agrees on the importance of protective gear, there are considerable issues pertaining to their weight, bulkiness, thickness, limited flexibility for free body movement, restricted permeability, and metabolic respiration, thus decreasing the willingness of potential users to wear protective clothing. Therefore, protection as well as comfort should be considered during the design and development of body armor. Hence, important factors, such as the types and characteristics of materials, design, thickness, concealment, integration between plates, protection class, and body armor weight must be taken into consideration throughout the whole process - from the concept of design to the product development itself. A high-performance material such as aramid is highly suitable to fulfill these requirements for bio-inspired vests, which help saving the lives of officers and ensure the desired comfort. The described body armor is under prototype development and will be subjected to testing to determine the optimal combination of comfort and protection. Thicker, bulkier, rigid, and larger/single plated armors can provide higher protection levels at the expense of comfort, in turn reducing acceptance by potential users. Although comfort is a legitimate concern, protection is always the prime requirement for stabresistant gear.

Currently, our team of researchers is studying the design and development of 3D printed stab-resistant armor based on the example of naturally occurring scales using aramid fibers due to their lightweight, durability, and high strength. Optimization of protection performance with the lowest possible thickness of scales and weight of the overall armor will be the main focus of the current research. All future research efforts in this field should simultaneously address comfort and protection performance, thereby increasing the willingness of armor users to wear armor frequently and regularly. 3D body scanning and $3 \mathrm{D}$ printing technologies can be employed to improve comfort by providing the necessary concealment, full flexibility, and great freedom of movement. The protection level and comfort of armors can be further improved by means of hybrid materials. For example, by the 3D printing of wool fiber and aramid or carbon fiber, two essential properties of the resulting 
stab-proof material can be guaranteed; this is because wool provides permeability and absorbency, whereas aramid or carbon ensures high impact resistance to puncture force.

The optimization of protection and comfort of body armor requires further research in terms of materials, design, technological flexibility including 3D printing technology, and the integration of electronic devices for communication, sensing situations, recording, and viewing of attackers from all directions. As a result, the wearers of protective gear could detect potential attacks earlier, thus giving them the chance to escape or prepare mentally for their defense.

\section{Acknowledgment}

Open Access Funding was covered by the Publication Fund of the TU Dresden

\section{References}

[1] Reiners $P$. Investigation about the stab resistance of textile structures, methods for their testing and improvements. HAL: Université de Haute Alsace; 2016.

[2] Fenne P. Protection against knives and other weapons. . Scott RA, editor. Cambridge: Woodhead Publishing, CRC; 2005.

[3] Alil L-C, Barbu C, Badea S, Ilie F. Aspects regarding the use of polyethylene fibers for personal armor. Eastern Michigan University. 2004.

[4] Cavallaro PV. Soft Body Armor: An Overview of Materials, Manufacturing, Testing, and Ballistic Impact Dynamics. In: Division NUWC, editor.: NUWCD-NPT-TR.; 2011.

[5] Laible R. Ballistic Materials and Penetration Mechanics (Methods and phenomena, their applications in science and technology): Elsevier; 2012.

[6] Justice NIo. Office of Justice Programs, U.S. Department of Justice. Stab Resistance of Personal Body Armor NIJ Standard-011500. Washington: US National Institute of Justice; 2000.

[7] LaTourrette T. The life-saving effectiveness of body armor for police officers. Journal of occupational and environmental hygiene. 2010;7(10):557-62. Epub 2010/07/17.

[8] Peleg K, Rivkind A, Aharonson-Daniel L. Does body armor protect from firearm injuries? Journal of the American College of Surgeons. 2006;202(4):643-8. Epub 2006/03/31.

[9] Jaslow CR. Mechanical properties pf cranal sutures. Journal of Biomechanical. 1990;23(4):313-21.

[10] Greaves I. Military Medicine in Iraq and Afghanistan: A Comprehensive Review: Taylor \& Francis Group, CRC Press; 2018.

[11] Ricciardi R, Deuster PA, Talbot LA. Metabolic Demands of Body Armor on Physical Performance in Simulated Conditions. MILITARY MEDICINE. 2008;173(9):817.

[12] Park H, Branson D, Petrova A, Peksoz S, Jacobson B, Warren $A$, et al. Impact of ballistic body armour and load carriage on walking patterns and perceived comfort. Ergonomics. 2013;56(7):1167-79. Epub 2013/05/10.
[13] Matusiak M. Thermal Comfort Index as a Method of Assessing the Thermal Comfort of Textile Materials FIBRES \& TEXTILES in Eastern Europe. 2010;18(2):4550.

[14] Voelker C, Hoffmann S, Kornadt O, Arens E, Zhang H, Huizenga $C$. Heat and moisture transfer through clothing. Eleventh International IBPSA Conference; Glasgow, Scotland: University of Strathclyde; 2009. p. 1360-6.

[15] Djongyang N, Tchinda R, Njomo D. Thermal comfort: A review paper. Renewable and Sustainable Energy Reviews. 2010;14(9):2626-40.

[16] Zehner GF, Ervin C, Robinette KM, Daziens P. Fit evaluation of female body armor. USA: 1987 Contract No.: AAMRL-TR-87-046.

[17] Larsen B, Netto K, Skovli D, Vincs K, Vu S, Aisbett B. Body armor, performance, and physiology during repeated highintensity work tasks. Military medicine. 2012;177(11):130815. Epub 2012/12/04.

[18] Chinevere TD, Cadarette BS, Goodman DA, Ely BR, Cheuvront SN, Sawka MN. Efficacy of body ventilation system for reducing strain in warm and hot climates. European journal of applied physiology. 2008;103(3):30714. Epub 2008/03/11.

[19] Nayak R, Crouch I, Kanesalingam S, Ding J, Tan P, Lee $B$, et al. Body armor for stab and spike protection, Part 1: Scientific literature review. Textile Research Journal. 2017;88(7):812-32.

[20] Nayak R, Kanesalingam S, Wang L, Padhye R. Stab resistance and thermophysiological comfort properties of boron carbide coated aramid and ballistic nylon fabrics. The Journal of The Textile Institute. 2018;110(8):1159-68.

[21] Holmes DA. Perfoirnance Characteristics of Waterproof Breathable Fabrics. JOURNAL OF INDUSTRIAL TEXTILES. 2000;29(4):306-16.

[22] Nayak R, Punj S, Chatterjee K, Behera BK. Comfort properties of suiting fabrics. Indian Journal of Fibre and Textile. 2009;34:122-8.

[23] philippe F, Schacher L, Adolphe DC, Dacremont C. Tactile Feeling: Sensory Analysis Applied to Textile Goods. Textile Research Journal. 2004;74(12):1066-72.

[24] Dempsey PC, Handcock PJ, Rehrer NJ. Impact of police body armour and equipment on mobility. Appl Ergon. 2013;44(6):957-61. Epub 2013/05/15.

[25] Legg SJ. Influence of body armour on pulmonary function. Ergonomics. 1988;31(3):349-53. Epub 1988/03/01.

[26] Ricciardi R, Deuster PA, Talbot LA. Effects of Gender and Body Adiposity on Physiological Responses to Physical Work While Wearing Body Armor. MILITARY MEDICINE. 2007;172(7):743.

[27] Armasure. Stab Knife Proof Concealable Covert Vest Jackets 36 Joules Body Armour-NIJ I Standard (24J/36J Overtest). UK: eBay Inc.; 2019.

[28] Courtney AC, Courtney MW. A thoracic mechanism of mild traumatic brain injury due to blast pressure waves. Medical hypotheses. 2009;72(1):76-83. Epub 2008/10/03.

[29] Xydakis MS, Fravell MD, Nasser KE, Casler JD. Analysis of battlefield head and neck injuries in Iraq and Afghanistan. Otolaryngology--head and neck surgery : official journal of American Academy of Otolaryngology-Head and Neck Surgery. 2005;133(4):497-504. Epub 2005/10/11. 
[30] Ritenour AE, Baskin TW. Primary blast injury: update on diagnosis and treatment. Critical care medicine. 2008;36(7 Suppl):S311-7. Epub 2008/07/18.

[31] Afshari M, Sikkema DJ, Lee K, Bogle M. High Performance Fibers Based on Rigid and Flexible Polymers. Polymer Reviews. 2008;48(2):230-74.

[32] Ambade VN, Godbole HV. Comparison of wound patterns in homicide by sharp and blunt force. Forensic Sci Int. 2006;156(2-3):166-70. Epub 2005/08/27.

[33] Hugar BS, Chandra G, Harish M, Jayanth S. Pattern of Homicidal Deaths. Journal of Indian Academy Forensic Medicine, 32(3). 2016;32(3).

[34] Henderson JP, Morgan SE, Patel F, Tiplady ME. Patterns of non-firearm homicide. Journal of clinical forensic medicine. 2005;12(3):128-32. Epub 2005/05/26.

[35] Scott RA. Textiles for Protection. 1 ed: Woodhead Publishing; 2005.

[36] Bleetman A, Watson CH, Horsfall I, Champion SM. Wounding patterns and human performance in knife attacks: optimising the protection provided by kniferesistant body armour. Journal of clinical forensic medicine. 2003;10(4):243-8. Epub 2004/07/28.

[37] Ahrendt D, Krzywinski S, Massot EJi, Krzywinski J. Hybrid material designs by the example of additive manufacturing for novel customized stab protective clothing. Light Weight Armour Group for Defense and Security; Roubaix, France2019. p. 286-94.

[38] Hainsworth SV, Delaney RJ, Rutty GN. How sharp is sharp? Towards quantification of the sharpness and penetration ability of kitchen knives used in stabbings. International journal of legal medicine. 2008;122(4):28191. Epub 2007/09/28.

[39] Horsfall I, Watson C, Champion S, Prosser P, Ringrose T. The effect of knife handle shape on stabbing performance. Appl Ergon. 2005;36(4):505-11. Epub 2005/05/17.

[40] Jones S, Nokesa L, Leadbeatterb S. The mechanics of stab wounding. Forensic Sci Int. 1994;67:59-63.

[41] ChadwickEKJ, NicolAC, Lane JV, Gray TGF. Biomechanics of knife stab attacks. Forensic Sci Int. 1999;105:35-44.

[42] Horsfall I. Stab resistant body armor: Cranfield University; 2000.

[43] Clerici CA, Muccino E, Gentile G, Marchesi M, Veneroni $L$, Zoja R. An unusual case of homicide with a crossbow and a hunting knife. Medicine, science, and the law. 2015;55(2):86-9. Epub 2014/06/18.

[44] Egres RG, Lee YS, Kirkwood JE, Kirkwood KM, Wetzel ED, Wagner NJ, editors. "Liquid armor": Protective fabrics utilizing shear thickening fluids. IFAL 4th International Conference on Safety and Protectve Fabrics; 2004; Pittsburgh, USA.

[45] Pounder DJ, Cormack L, Broadbent E, Millar J. Class characteristics of serrated knife stabs to cartilage. The American journal of forensic medicine and pathology. 2011;32(2):157-60. Epub 2010/04/22.

[46] Li Y, Ortiz C, Boyce MC. Bioinspired, mechanical, deterministic fractal model for hierarchical suture joints. Physical review E, Statistical, nonlinear, and soft matter physics. 2012;85(3):031901(14). Epub 2012/05/17.

[47] Ji B, Gao H. Mechanical properties of nanostructure of biological materials. Journal of the Mechanics and Physics of Solids. 2004;52(9).
[48] Barthelat F, Tang H, Zavattieri D, Li C, Espinosa D. On the mechanics of mother-of-pearl: A key feature in the material hierarchical structure. Journal of the Mechanics and Physics of Solids. 2007;55(2):306-37.

[49] Pritchard J, Scott J, Girgis G. The structure and development of cranial and facial sutures. Journal of Anatomy. 1956;90(1):73-86.

[50] Herring SW. Mechanical influences on suture development and patency. Frontiers of oral biology. 2008;12:41-56. Epub 2008/04/09.

[51] Krauss S, Monsonego-Ornan E, Zelzer E, Fratzl P, Shahar R. Mechanical Function of a Complex Three-Dimensional Suture Joining the Bony Elements in the Shell of the RedEared Slider Turtle. Advanced Materials. 2009;21(4):40712.

[52] Garcia AP, Pugno N, Buehler MJ. Superductile, Wavy Silica Nanostructures Inspired by Diatom Algae. Advanced Engineering Materials. 2011;13(10):B405-B14.

[53] Dunlop JWC, Weinkamer R, FratzI P. Artful interfaces within biological materials. Materials Today. 2011;14(3):70-8.

[54] Vernerey FJ, Barthelat F. On the mechanics of fishscale structures. International Journal of Solids and Structures. 2010;47(17):2268-75.

[55] Dastjerdi AK, Barthelat F. Teleost fish scales amongst the toughest collagenous materials. J Mech Behav Biomed Mater. 2015;52:95-107. Epub 2014/12/03.

[56] Zhu D, Szewciw L, Vernerey F, Barthelat F. Puncture resistance of the scaled skin from striped bass: collective mechanisms and inspiration for new flexible armor designs. J Mech Behav Biomed Mater. 2013;24:30-40. Epub 2013/05/21.

[57] Lin YS, Wei CT, Olevsky EA, Meyers MA. Mechanical properties and the laminate structure of Arapaima gigas scales. J Mech Behav Biomed Mater. 2011;4(7):1145-56. Epub 2011/07/26.

[58] Connors MJ, Ehrlich H, Hog M, Godeffroy C, Araya S, Kallai I, et al. Three-dimensional structure of the shell plate assembly of the chiton Tonicella marmorea and its biomechanical consequences. Journal of structural biology. 2012;177(2):314-28. Epub 2012/01/18.

[59] Martini R, Balit Y, Barthelat F. A comparative study of bio-inspired protective scales using $3 D$ printing and mechanical testing. Acta biomaterialia. 2017;55:360-72. Epub 2017/03/23.

[60] Suzuki Y, Kopp R, Kogure T, Suga A, Takai K, Tsuchida $S$, et al. Sclerite formation in the hydrothermal-vent "scaly-foot" gastropod-possible control of iron sulfide biomineralization by the animal. Earth and Planetary Science Letters. 2006;242(1-2):39-50.

[61] Pangolin-Conservation-Support-Initiative. Save Pangolins. 2019.

[62] Chintapalli RK, Mirkhalaf M, Dastjerdi AK, Barthelat F. Fabrication, testing and modeling of a new flexible armor inspired from natural fish scales and osteoderms. Bioinspiration \& biomimetics. 2014:9(3):036005. Epub 2014/03/13

[63] Browning A, Ortiz C, Boyce MC. Mechanics of composite elasmoid fish scale assemblies and their bioinspired analogues. J Mech Behav Biomed Mater. 2013;19:75-86. Epub 2013/03/23. 
[64] Porter M, Ravikumar N, Barthelat F, Martini R. 3D-printing and mechanics of bio-inspired articulated and multimaterial structures. Jour-nal of the mechanical behavior of biomedical materials. 2017;73:114-26.

[65] Yang W, Chen I, Gludovatz B, Zimmermann E, Ritchie $R$, Meyers M. Natural flexible dermal armor. Advanced Materials. 2013;25(1):31-48.

[66] Bruet BJ, Song J, Boyce MC, Ortiz C. Materials design principles of ancient fish armour. Nature materials. 2008;7(9):748-56. Epub 2008/07/29.

[67] Li Y, Ortiz C, Boyce MC. Stiffness and strength of suture joints in nature. Physical review E, Statistical, nonlinear, and soft matter physics. 2011;84(6 Pt 1):062904. Epub 2012/02/07

[68] Zhang Y, Yao H, Ortiz C, Xu J, Dao M. Bio-inspired interfacial strengthening strategy through geometrically interlocking designs. J Mech Behav Biomed Mater. 2012;15:70-7. Epub 2012/10/04.

[69] Li Y, Ortiz C, Boyce MC. A generalized mechanical model for suture interfaces of arbitrary geometry. Journal of the Mechanics and Physics of Solids. 2013;61(4):1144-67.

[70] Vernerey FJ, Barthelat F. Skin and scales of teleost fish: Simple structure but high performance and multiple functions. Journal of the Mechanics and Physics of Solids. 2014;68:66-76

[71] Lee YS, Wetzel ED, Wagner NJ. The ballistic impact characteristics of Kevlar ${ }^{\circledR}$ woven fabrics impregnated with a colloidal shear thickening fluid. Journal of Materials Science. 2003;38(13):2825-33.

[72] Guzman AG, Geddis AM, Henrich MJ, Lohrstorfer CF, Neuman SP. Summary of air permeability data from single-hole injection tests in unsaturated fractured tuffs at the Apache Leap Research Site: Results of steady-state test interpretation. ; Nuclear Regulatory Commission, Washington, DC (United States). Div. of Regulatory Applications; Arizona Univ., Tucson, AZ (United States). Dept. of Hydrology and Water Resources, 1996 NUREG/ CR-6360; Other: ON: TI96009930; TRN: 96:011321 United States 10.2172/219309 Other: ON: TI96009930; TRN: 96:011321 INIS; OSTI as TI96009930 OSTI English.

[73] Barker J, Black C, Cloud R. Comfort comparison of ballistic vest panels for police officers. Journal of Textile and Apparel, Technology and Management. 2010;6(3):112.

[74] El Messiry M, Eltahan E. Stab resistance of triaxial woven fabrics for soft body armor. Journal of Industrial Textiles. 2014;45(5):1062-82.

[75] Flambard X, Ferreira $M$, Vermeulen B, Bourbigot $S$. Mechanical and thermal behaviors of first choice, second choice and recycled p-aramid fibers. Journal of Textile and Apparel, Technology and Management. 2004;4(1):1-12.

[76] Decker MJ, Halbach CJ, Nam CH, Wagner NJ, Wetzel $E D$. Stab resistance of shear thickening fluid (STF)-treated fabrics. Composites Science and Technology. 2007;67(34):565-78.

[77] Shin H-S, Erlich DC, Simons JW, Shockey DA. Cut Resistance of High-strength Yarns. Textile Research Journal. 2016;76(8):607-13.

[78] Hosur MV, Mayo Jr JB, Wetzel E, Jeelani S. Studies on the Fabrication and Stab Resistance Characterization of Novel Thermoplastic-Kevlar Composites. Solid State Phenomena. 2008;136:83-92.
[79] Crouch IG. Body armour - New materials, new systems. Defence Technology. 2019;15(3):241-53.

[80] Tavanai H, Wang L, Golozar M, Ebrahimzade M. An investigation on the piercing resistance of abrasive particle coated fabrics. The 1st International and the 7th National Iranian Textile Engineering Conference; Iran: ACECRAmirkabir University of Technology Branch; 2009.

[81] Govarthanam KK, Anand SC, Rajendran S. Handbook of technical textiles. 2 ed. UK: Matthew Deans; 2016.

[82] Lee BL, Walsh TF, Won ST, Patts HM, Song JW, Mayer AH. Penetration Failure Mechanisms of Armor-Grade Fiber Composites under Impact. Journal of Composite Materials. 2016;35(18):1605-33.

[83] Shim VPW, Lim CT, Foo KJ. Dynamic mechanical properties of fabric armour. International Journal of Impact Engineering. 2001;25(1):1-15.

[84] McConnell VP. Ballistic protection materials a moving target. Reinforced Plastics. 2006;50(11):20-5.

[85] Rebouillata S, Pengb J, Donnetb J. Surface structure of Kevlarw fiber studied by atomic force microscopy and inverse gas chromatography. Polymer. 1999;40:7341-50.

[86] Hani ARA, Roslan A, Mariatti J, Maziah M. Body Armor Technology: A Review of Materials, Construction Techniques and Enhancement of Ballistic Energy Absorption. Advanced Materials Research. 2012;488489:806-12.

[87] Teijin A. Twaron-a versatile high-performance fibre. company product. 2012 40-00-01.

[88] Tien DT, Kim JS, Huh Y. Stab-resistant property of the fabrics woven with the aramid/cotton core-spun yarns. Fibers and Polymers. 2010;11(3):500-6.

[89] Sinnappoo K, Arnold L, Padhye R. Application of wool in high-velocity ballistic protective fabrics. Textile Research Journal. 2010;80(11):1084-92.

[90] Reiners P, Kyosev Y, Schacher L, Adolphe D, Küster $K$. Experimental investigation of the influence of wool structures on the stab resistance of woven body armor panels. Textile Research Journal. 2015;86(7):685-95.

[91] Phillips M, Bazrgari B, Shapiro R. The effects of military body armour on the lower back and knee mechanics during toe-touch and two-legged squat tasks. Ergonomics. 2015;58(3):492-503. Epub 2014/10/25.

[92] Konitzer LN, Fargo MV, Brininger TL, Reed LM. Association between back, neck, and upper extremity musculoskeletal pain and the individual body armor. Journal of Hand Therapy. 2008;21(2):143-9.

[93] Barker JF. Comfort Perceptions of Police Officers Toward Ballistic Vests. Tallahassee, Florida: Florida State University; 2007.

[94] Rupp J, Böhringer A, Yonenaga A, Hilden J. Textiles for protection against harmful ultraviolet radiation. International Textile Bulletin. 2001;47(6):8-20.

[95] Sparks E, editor. Advances in Military Textiles and Personal Equipment: Woodhead publishing; 2012.

[96] Yuan MQ, Liu Y, Gong Z, Qian XM. The application of PA/ CF in stab resistance body armor. IOP Conference Series: Materials Science and Engineering. 2017;213:012027.

[97] Croft J, Longhurst D, Branch GBHOSD. HOSDB Body Armour Standards for UK Police (2007): Criminal Justice System Race Unit, The Home Office; 2007. 
[98] Institut OotDHdPP. Test Standard Stab and Impact Resistance. Requirements, classifications and test procedures. Deutchland: Vereinigung der Prüfstellen für angriffshemmende Materialien und Konstruktionen (VPAM); 2011.

[99] ASTM-D737. Test Method for Air Permeability of Textile Fabrics. West Conshohocken, PA: ASTM International; 2004.

[100] ASTM-D5470. Standard Test Method for Thermal Transmission Properties of Thermally Conductive Electrical Insulation Materials. West Conshohocken, PA: ASTM International; 2017.
[101] ISO-811:2018(en). Textiles - Determination of resistance to water penetration - Hydrostatic pressure test. International Organization for Standardization; 2018.

[102] ASTM-D1388. Standard Test Method for Stiffness of Fabrics. West Conshohocken, PA: ASTM International; 2018.

[103] ISO-13998:2003(en). Protective clothing- Aprons, trousers and vests protecting against cuts and stabs by hand knives. International Organization for Standardization; 2003. 